\title{
The Loss and Progressive Recovery of Voiding after Spinal Cord Interruption in Rats is Associated with Simultaneous Changes in Autonomous Contractile Bladder Activity
}

\author{
Thomas Gevaert $^{a, *}$, Grzegorz Owsianik ${ }^{b}$, Graham Hutchings $^{a}$, Liesbeth Van Leuven $^{a}$, \\ Wouter Everaerts $^{a}$, Bernd Nilius ${ }^{b}$, Dirk De Ridder ${ }^{a}$ \\ ${ }^{\text {a }}$ KU Leuven, Department of Urology, University Hospitals Gasthuisberg, Leuven, Belgium \\ ${ }^{\mathrm{b}}$ KU Leuven, Department of Mol Cell Biology, Division of Physiology, Laboratory of Ion Channel Research, Campus Gasthuisberg, \\ Herestraat 49, bus 802, B-3000 Leuven, Belgium
}

\section{Article info}

Article history:

Accepted June 12, 2008

Published online ahead of print on June 26, 2008

\section{Keywords:}

Autonomous activity

$\mathrm{M}_{2}$

$\mathrm{M}_{3}$

Overactive bladder

Spinal cord injury

Please visit

www.europeanurology.com

and www.urosource.com to

view the accompanying figure.

\begin{abstract}
Background: Autonomous contractile activity (ACA) is a well-known phenomenon in isolated bladders from different species and seems to be important in the physiology of both normal and dysfunctional voiding.

Objective: To determine whether ACA is changed in bladders from paraplegic rats at different periods post-spinal cord injury (post-SCI).

Design, setting, and participants: ACA was studied in bladders (at least six per group) from normal and paraplegic female Wister rats at different times post-SCI ( $2 \mathrm{~h}, 24 \mathrm{~h}, 1 \mathrm{wk}$, and $3 \mathrm{wk}$ ). A group of normal rats was used as a control group. For measurements bladders were incubated in organ baths under standardised conditions.

Measurements: ACA was measured as pressure change, which was defined as either a transient change or a spiked change according to its characteristics. The effects of intravesical volume load and muscarinic agonists were studied.

Results and limitations: Following spinal cord injury (SCI) a clear evolution in ACA was observed. In bladders from SCI rats in the acute areflexive voiding phase (1 wk post-SCI), we observed decreased ACA associated with a highly increased compliance and a changed response to muscarinic agonists. ACA in bladders from SCI rats with renewed voiding reflexes ( $3 \mathrm{wk}$ post-SCI) was increased, together with a moderately increased compliance and a (moderately) changed response to muscarinic agonists.

Conclusions: From these observations it is apparent that $\mathrm{SCl}$ leads to alterations in the behaviour and muscarinic response of ACA in the isolated bladder. These changes in ACA may play an important role in the pathophysiology of overactive bladder disease $(\mathrm{OAB})$, and interacting with changed $A C A$ might be promising in the search for newer treatments for OAB.
\end{abstract}

(C) 2008 European Association of Urology. Published by Elsevier B.V. All rights reserved.

ding author. University Hospitals Gasthuisberg, Department of Urology, Herestraat 49, 3000 Leuven, Belgium. Tel. +321646930; Fax: +3216346931.

E-mail address: Thomas.gevaert@uz.kuleuven.ac.be (T. Gevaert). 


\section{Introduction}

The most common functional bladder disorder is overactive bladder disease $(\mathrm{OAB})$, which is a syndrome of urinary urgency with or without urge incontinence, usually with frequency and nocturia [1]. OAB with a neurological aetiology is often referred to as neurogenic detrusor overactivity (NDO). The study of the pathophysiology of NDO has mainly considered changes in bladder innervation [2], but at present there is no integrative functional bladder model that can fully explain the mechanisms underlying NDO. Recent reports have suggested that alterations in autonomous contractile bladder activity (ACA) might also play an important role in the aetiology and clinical image of functional bladder disorders [3-5]. Exaggerated and increased ACA might be partially responsible for generating nonvoiding contractions (NVC) and increased sensations of urge $[3,5,6]$.

A frequently used animal model to study NDO is the spinal cord injured rat with a full spinal cord lesion at the thoracic vertebral levels T9-T12. Bladder function in such spinal cord injured rats has some well-described timedependent evolutions, finally resulting in NDO. It is known that during the first $4 \mathrm{~d}$ post-spinal cord injury (post-SCI) rats exhibit detrusor areflexia [7,8], followed by the emergence of NVC from day 5 [7,8]. After 2-3 wk postSCI bladder contractions gradually produce loss of urine, which results in a partial recovery of voiding function [7-9]. However, voiding is then inefficient due to detrusorsphincter dyssynergia and is accompanied by uninhibited bladder contractions (NVC) [7,9].

In the present study we looked at ACA in bladders from $\mathrm{SCI}$ rats at different clinical stages in the development of NDO: during spinal shock ( $2 \mathrm{~h}$ post-SCI), during detrusor areflexia ( $24 \mathrm{~h}$ post-SCI), during the onset of NVC (1 wk post-SCI), and finally during the recovery of (dysfunctional) spontaneous voiding ( $3 \mathrm{wk}$ post-SCI). Our aim was to investigate whether SCI induces alterations in the behaviour of ACA that could be involved in the evolution from detrusor areflexia towards NDO.

\section{Methods}

Rats used were female Wister rats (weight: 200-250 g; age: 10-14 wk; Elevage Janvier, Le Genest St Isle, France). All rats were housed according to the rules of the Institutional Animal Ethics Committee, and appropriate ethical approval was obtained for these experiments. Rats were sacrificed using $\mathrm{CO}_{2}$ overdose at four different time periods after SCI: $2 \mathrm{~h}, 24 \mathrm{~h}, 1 \mathrm{wk}$, and $3 \mathrm{wk}$.

\subsection{Procedures on animals}

SCI was performed under 3.5\% isoflurane anaesthesia (Isoba, SheringPlough, Uxbridge, UK) and prophylaxis with antibiotics $(0.6 \mathrm{ml}$ ampicillin [100 mg/ml], Duphamox, Norbrook Laboratories, Newry, Northern Ireland). The procedure involved a laminectomy at the vertebral level T8-T9, interrupting the spinal cord at T9 and closing the surgical wound. A crédé-manoeuvre-emptying the bladder by application of smooth abdominal pressure-was performed twice daily, and antibiotics were given every $2 \mathrm{~d}$ during the first week. After surgery, attention was given to thermoregulation and to prevention and treatment of decubitus lesions.

Volume of urine in bladder was estimated by measuring the amount of urine collected by crédé manoeuvres in rats from all groups (at least 10 animals per group). This urine collection was always performed in the morning to exclude diurnal variability in urine production.

\subsection{Pressure measurements}

Animals were sacrificed and a laparotomy was performed. A small catheter (22 gauge, Insyte-W, Becton-Dickinson, Aalst, Belgium) was inserted in the urethra for transurethral pressure measurement and secured with a ligature. The bladder was then excised entirely after ligation of both ureters. A strict time schedule was maintained following bladder excision. The bladder was excised at minute 0 and directly placed in cold Krebs ( $\mathrm{NaCl} 118 \mathrm{mmol} / \mathrm{l}, \mathrm{KCl} 4.6 \mathrm{mmol} / \mathrm{l}, \mathrm{CaCl}_{2} 2.5 \mathrm{mmol}$, $\mathrm{MgSO}_{4} 1.2 \mathrm{mmol} / \mathrm{l}, \mathrm{KH}_{2} \mathrm{PO}_{4} 1.2 \mathrm{mmol} / \mathrm{l}, \mathrm{NaHCO}_{3} 25 \mathrm{mmol} / \mathrm{l}$, glucose $11 \mathrm{mmol} / \mathrm{l}$, ultra pure water; $4^{\circ} \mathrm{C}$ ). The bladder was then placed in a heated organ bath at minute 5 , and the first measurements were made approximately $30 \mathrm{~min}$ later. The incubation fluid was Krebs solution. This was constantly gassed with a mixture of oxygen (95\%) and $\mathrm{CO}_{2}(5 \%)$, and the temperature was maintained at a mean of $36^{\circ} \mathrm{C}$ with a pH of 7.40. The intraurethral catheter was connected via a three-way tap to a volume pump (Harvard Apparatus, Holliston, MA, USA) to allow increase of intravesical volume and to a DTX plus pressure transducer (BectonDickinson, Aalst, Belgium; zero offset $25 \mathrm{mmHg}$, natural frequency $100 \mathrm{~Hz}$ ), from which the output was amplified and recorded using the Windaq system (Dataq Instruments, Akron, OH, USA). Pressure transducers were calibrated before every experiment.

Each experiment consisted of two parts. First the bladder capacity was established. In the absence of a formal definition of capacity in the isolated bladder, we used the definition of hydromechanical capacity as described previously [3], although some adaptations were made. Bladders were allowed to adapt their volume spontaneously at $36^{\circ} \mathrm{C}$, and the intravesical baseline pressure at that volume was set at $0 \mathrm{~cm} \mathrm{H}_{2} \mathrm{O}$. Successively, bladders were filled at $20 \mu \mathrm{l} / \mathrm{min}$, and the volume at which baseline pressure had increased with a constant pressure of $0.5 \mathrm{~cm} \mathrm{H}_{2} \mathrm{O}$ was considered as hydromechanical capacity $(580 \pm 12 \mu \mathrm{l}$ in the control group vs $1370 \pm 36 \mu \mathrm{l}$ at $3 \mathrm{wk}$ post-SCI). In volume-load experiments we let bladders spontaneously adapt their volume to $36^{\circ} \mathrm{C}$, and successively we started bladder filling. This different protocol was used to obtain fair compliance data. Once bladder capacity was established, the experimental measurements were performed. For volume load, pressures were measured during $45 \mathrm{~min}$ with $15 \mathrm{~min}$ of resting status, $15 \mathrm{~min}$ of filling status at a rate of $20 \mu \mathrm{l} / \mathrm{min}$ (with Krebs solution), and $15 \mathrm{~min}$ of resting status after the filling phase. For muscarinic responses, cumulative doses were added every $5 \mathrm{~min}$ (carbachol $10^{-8.5}$ $10^{-6} \mathrm{M}$, arecaïdine but-2-ynyl ester tosylate (ABET) $10^{-9.5}-10^{-7} \mathrm{M}$ ). All drugs were added in volumes of $100 \mu \mathrm{l}$ from a stock solution. Bladders were weighed after each experiment. Each experiment was performed on at least six whole bladders per group.

\subsection{Drugs}

Drugs used were the nonselective muscarinic agonist carbachol (Sigma, Bornem, Belgium) and the weak partial $\mathrm{M}_{2}$-agonist ABET (pD2 for $\mathrm{M}_{2}=8.33$ and pD2 for $\mathrm{M}_{3}=7.67$ [10]; Tocris, Bristol, UK). All drugs were dissolved in purified water, made as stock solutions, and stored at $4{ }^{\circ} \mathrm{C}$.

\subsection{Analytic definitions and statistical analysis}

All analyses were performed during equal time periods. ACA was measured as change in intravesical pressure, and for statistical comparison pressure values were normalised to bladder weight. 
Consistent with previous publications we divided intravesical pressure change into two groups [3,11]. Transients were defined as pressure changes of at least $0.5 \mathrm{~cm} \mathrm{H}_{2} \mathrm{O}$, lasting between $5 \mathrm{~s}$ and $30 \mathrm{~s}$, and ending when the pressure level had fallen to $25 \%$ of its original height. Spikes were defined as pressure changes of at least $0.1 \mathrm{~cm} \mathrm{H}_{2} \mathrm{O}$, lasting between $0 \mathrm{~s}$ and $3 \mathrm{~s}$, and ending when the pressure level had returned to the initial baseline. Compliance was calculated using the following formula: volume load $(\mathrm{ml}) /$ increase in baseline pressure normalised to bladder weight $\left(\Delta \mathrm{cm} \mathrm{H}_{2} \mathrm{O} / \mathrm{g}\right)$. All cholinergic effects on ACA were calculated relative to baseline values and expressed as increases in amplitude or baseline. Cholinergic concentration-response curves are graphically presented by fitting sigmoidal curves to the experimental data (Graphpad Prism software, San Diego, USA). Potencies are expressed as $\mathrm{pD} 2$ values $(=-\log$ EC50).

Quantitative values are shown as the mean plus or minus standard error. Statistics were performed with Statistica 7.1 (Statsoft, Tulsa, OK, USA). An analysis-of-variance (ANOVA) test was used to compare different groups, followed by a Fisher post hoc test.

\subsection{Quantitative polymerase chain reaction}

Dissected bladders were incubated in $\mathrm{Ca}^{2+} / \mathrm{Mg}^{2+}$-free medium (Invitrogen, Merelbeke, Belgium). Instant quantitative polymerase chain reactions (QPCR) were performed in triplicate using cDNA generated from whole bladder mRNAs ( $n=4$ per group) and specific rat $\mathrm{M}_{2}$ (muscarinic receptor, Rn02532311_s1; Applied Biosystems) and $\mathrm{M}_{3}$ (Rn01470216_m1; Applied Biosystems) TaqMan assays. The housekeeping gene $\beta$-actin (Applied Biosystems), which remained constant post-SCI (data not shown), was used as an endogenous control to normalise $\mathrm{M}_{2} / \mathrm{M}_{3}$ mRNA. Data (mean plus or minus SE) are shown as an $x$-fold expression of detected mRNA normalised to $\mathrm{M}_{3}$ mRNA in bladders of adult rats, which was used as a calibrator for the comparative critical threshold $(\Delta \Delta \mathrm{Ct})$ analysis.

\section{Results}

\subsection{Bladder weight and bladder volume post-spinal cord injury (Fig. 1)}

Volume of urine in bladder showed a steady increase postSCI, reaching its maximum at 1 wk post-SCI $(p<0.005)$. Bladder weight was significantly increased at $1 \mathrm{wk}$ and $3 \mathrm{wk}$ post-SCI ( $p<0.005$ ). (Voiding behaviour of rats post-SCI is shown in Supplementary Fig. 1).

\subsection{Behaviour of autonomous contractile activity post-spinal cord injury (Fig. 2)}

The frequency of transients decreased progressively post-SCI, reaching its lowest value at $1 \mathrm{wk}$ post-SCI $(p<0.005)$. The amplitude of transients globally increased at $2 \mathrm{~h}$ post-SCI $(p<0.005)$. From $24 \mathrm{~h}$ post-SCI onward, the duration of transients became significantly longer $(p<0.005)$. The frequency of spikes decreased until $1 \mathrm{wk}$ post-SCI $(p<0.005)$; at $3 \mathrm{wk}$ post-SCI the frequency of spikes became higher compared to controls $(p<0.05)$.

\subsection{Volume-induced changes in autonomous contractile activity post-spinal cord injury (Fig. 3)}

Compliance increased post-SCI, reaching its highest value at 1 wk post-SCI $(p<0.005)$. The volume-induced increase in
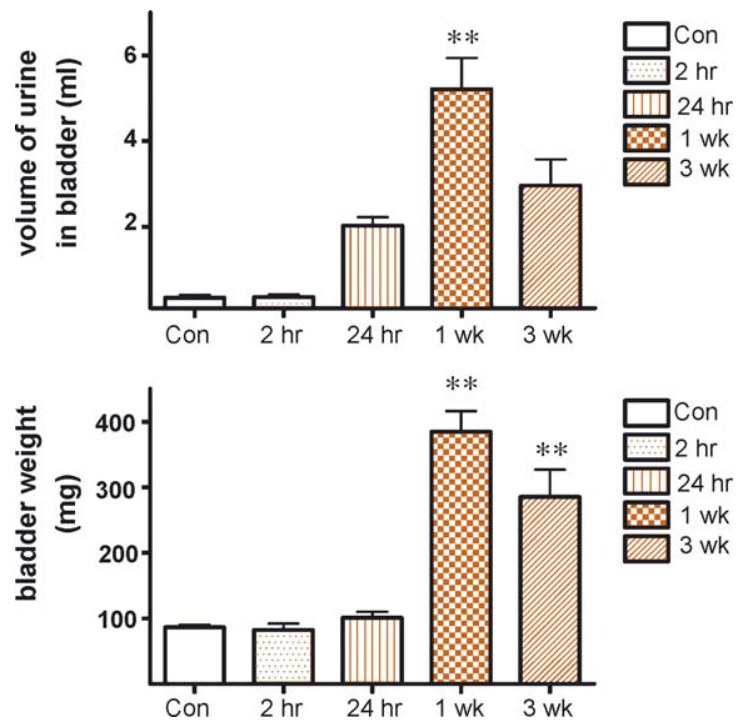

Fig. 1 - Graphs illustrating bladder weight and volume of urine in bladder at different periods post-spinal cord injury (post-SCI). Maximal values of both parameters were observed around $1 \mathrm{wk}$ post-SCI. An asterisk $\left({ }^{*}\right)$ indicates significance $\left({ }^{*} p<0.05 ;{ }^{* *} p<0.005\right)$. Significance values in bladders post-SCI are always compared to normal bladder values. Only the most relevant significance levels are indicated. Data are means plus or minus SE.

contractile amplitude of transients decreased significantly only at $2 \mathrm{~h}$ post-SCI $(p<0.05)$. The volume-induced increase in frequency of transients was impaired at periods later than $24 \mathrm{~h}$ post-SCI, resulting in larger statistical differences between different groups $(p<0.005)$. Volume had no obvious effects on frequency of spikes in all of the studied groups.

\subsection{Response to muscarinic agonists post-spinal cord injury (Figs. 4 and 5)}

Carbachol induced an increase in amplitude of transients and baselines in all groups, which was significantly more pronounced in bladders $2 \mathrm{~h}$ post-SCI $(p<0.005)$. PD2values for carbachol effects on amplitude and baseline were significantly increased between $2 \mathrm{~h}$ post-SCI and $1 \mathrm{wk}$ post$\mathrm{SCI}$ compared to controls; at $3 \mathrm{wk}$ post-SCI pD2 values were again similar to controls [for amplitude: $p<0.05$; mean plus or minus SE (group): $6.5 \pm 0.4$ (control), $6.8 \pm 0.2(2 \mathrm{~h}$ ), $7.0 \pm 0.2(24 \mathrm{~h}), 8.2 \pm 2.5(1 \mathrm{wk})$, and $6.8 \pm 0.3$ (3 wk); for baseline: $p<0.05$; mean plus or minus SE (group): $7.2 \pm 0.2$ (control), $7.6 \pm 0.2(2 \mathrm{~h}), 7.7 \pm 0.3(24 \mathrm{~h}), 7.6 \pm 0.1(1 \mathrm{wk})$, and $7.3 \pm 0.1$ ( $3 \mathrm{wk})]$. The weak $\mathrm{M}_{2}$-selective drug ABET induced significantly larger increases in contractile amplitude in bladders 1 wk post-SCI compared to other groups post-SCI $(p<0.005)$ and compared to controls $(p<0.005)$. In groups $24 \mathrm{~h}$ post-SCI and $3 \mathrm{wk}$ post-SCI this increase was less pronounced but mostly still significant compared to controls $(p<0.05)$; in controls the increase in contractile amplitude to ABET was negligible (Figs. 4 and 5). PD2-values for ABET effects on amplitude were decreased at $1 \mathrm{wk}$ post-SCI and 3 wk post-SCI compared to controls, although not significantly [mean plus or minus SE (group): $9.3 \pm 0.6$ (control), $9.3 \pm 0.7$ ( $2 \mathrm{~h}), 9.1 \pm 0.5$ (24 h), $8.4 \pm 0.4$ (1wk) and $7.7 \pm 0.3$ (3 wk)]. An increase in the contractile baseline due to ABET became 


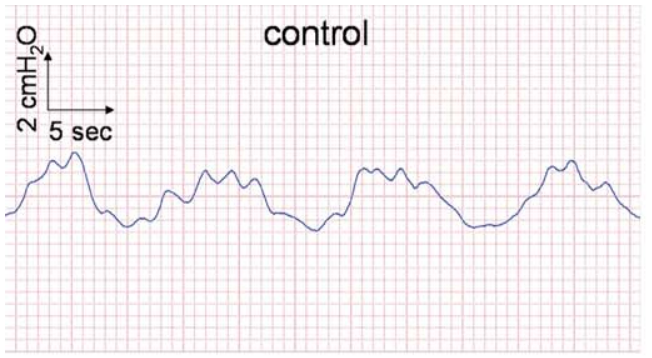

2 hours post-SCI

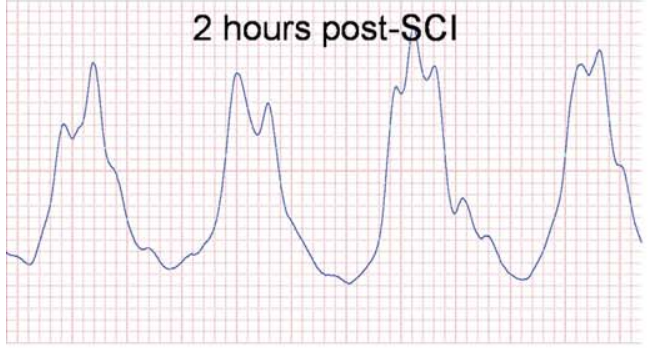

24 hours post-SCI

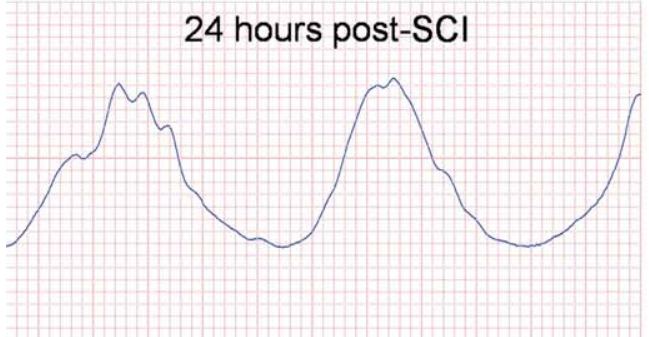

1 week post-SCI

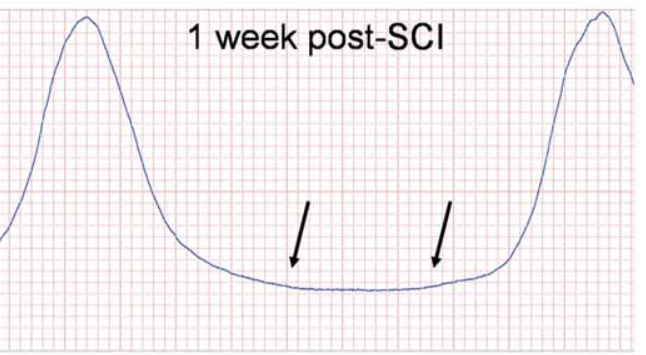

3 weeks post-SCI

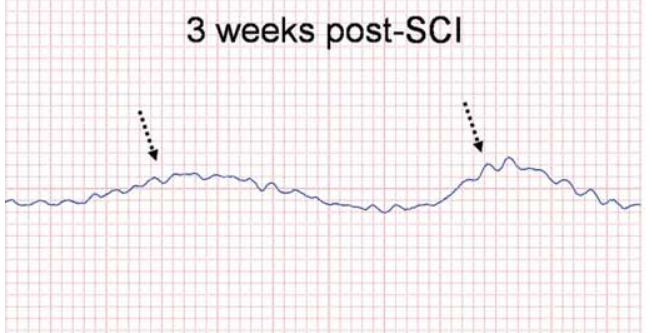

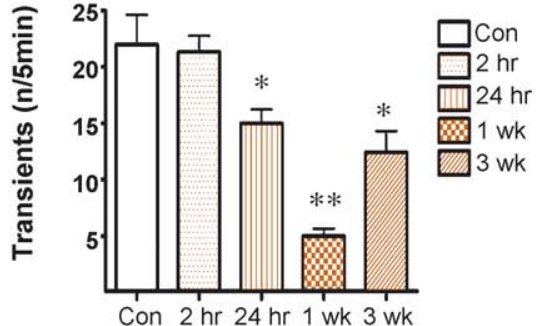
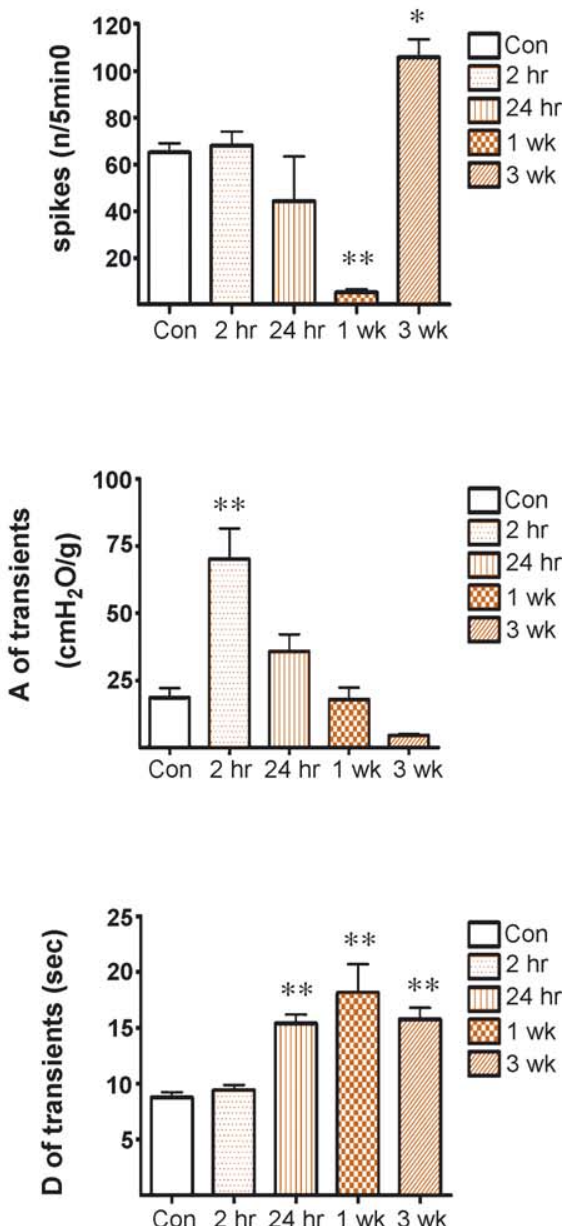

Fig. 2 - Autonomous contractile activity (ACA) at different periods post-spinal cord injury (post-SCI). Left panels: pattern of ACA at different periods postSCI: control, 2 h post-SCI, $24 \mathrm{~h}$ post-SCI, 1 wk post-SCI, and 3 wk post-SCI. The contractile frequency of ACA is significantly decreased at 1 wk post-SCI (long intervals, full arrows). At 3 wk post-SCI, ACA becomes irregular and exaggerated (abundant spikes, broken arrows). Pressure and time scales are the same in all panels. Right panels: Graphs illustrating evolution of different contractile parameters post-SCI: frequency of transients, frequency of spikes, amplitude (A) and duration (D) of transients. An asterisk $\left({ }^{*}\right)$ indicates significance $\left({ }^{*} p<0.05 ;{ }^{* *} p<0.005\right)$. Significance levels in bladders post-SCI are always compared to normal bladder values. Only the most relevant significances are indicated. Data are means plus or minus SE.

apparent at higher drug concentrations, most pronounced (but without significance) in bladders at $1 \mathrm{wk}$ post-SCI. Potency for ABET effects on baseline decreased post-SCI compared to controls; therefore accurate $\mathrm{pD} 2$ values for post$\mathrm{SCI}$ groups could not be generated [mean plus or minus SE: $8.2 \pm 0.4$ (control)].
3.5. Quantitative polymerase chain reaction data on $\mathrm{M} 2$ and M3 in whole bladders post-spinal cord injury (Fig. 6)

QPCR showed a significant increase of $\mathrm{M}_{2}$ mRNA in bladders at $3 \mathrm{wk}$ post-SCI compared to controls ( $p<0.05$ ), but no changes were observed at earlier stages post-SCI. The 

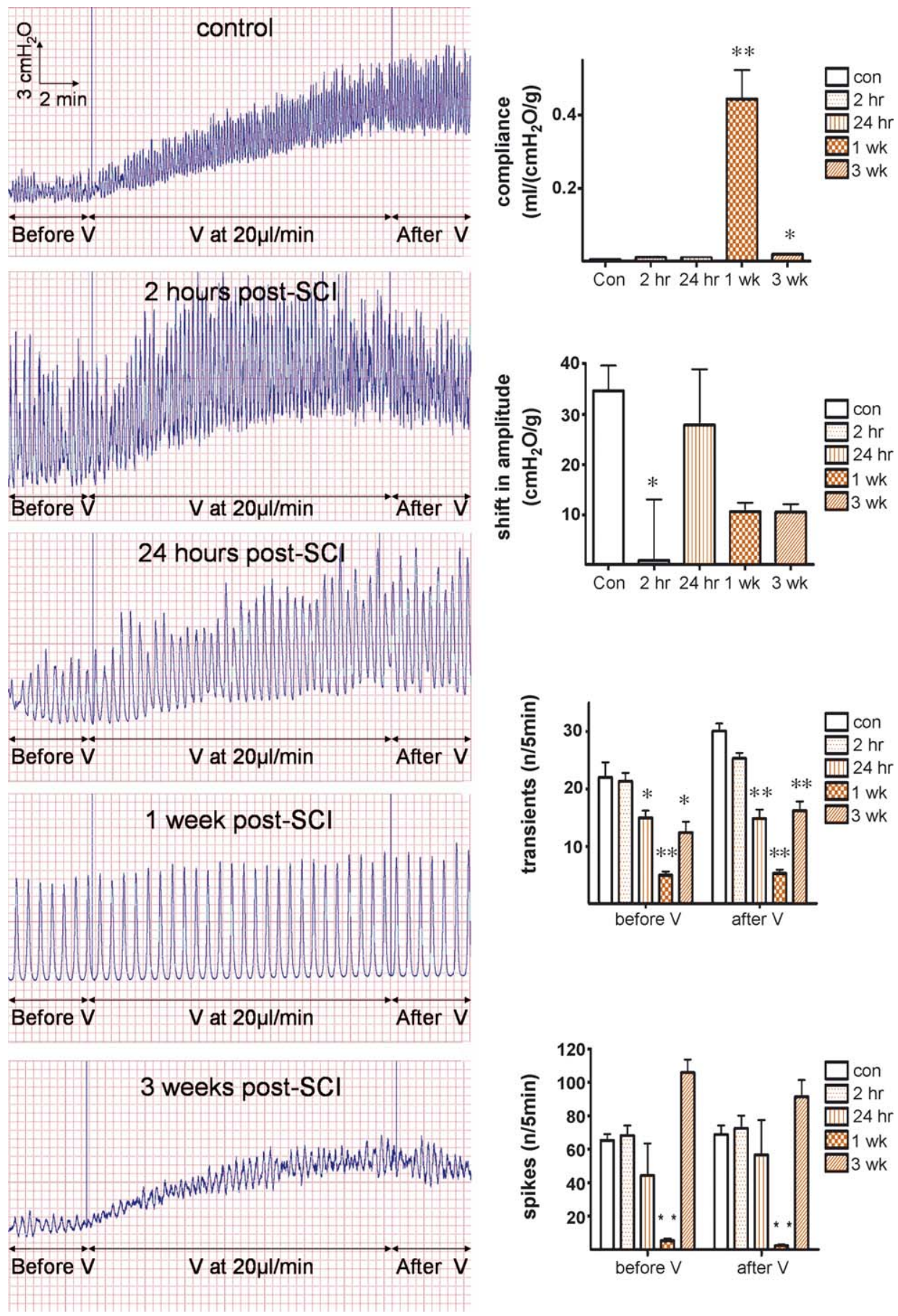

Fig. 3 - Effects of intravesical volume on autonomous contractile activity (ACA) at different periods post-spinal cord injury (post-SCI). Left panels: pattern of volume-induced effects $(20 \mu \mathrm{l} / \mathrm{min})$ on ACA at different periods post-SCI: control, $2 \mathrm{~h}$ post-SCI, $24 \mathrm{~h}$ post-SCI, 1 wk post-SCI, and 3 wk post-SCI. Pressure and time scales are the same in all panels. Right panels: Graphs illustrating volume-induced effects on ACA at different periods post-SCI: effects of intravesical volume load $(20 \mu \mathrm{l} / \mathrm{min})$ on compliance, on amplitude and frequency of transients, and on spikes. An asterisk $\left({ }^{*}\right)$ indicates significance $\left({ }^{*} p<0.05 ;{ }^{* *} p<0.005\right)$. Significance values in bladders post-SCI were always compared to normal bladder values. Only the most relevant significances are indicated. Data are means plus or minus SE.

amount of $\mathrm{M}_{3}$ mRNA had significantly decreased in bladders at $24 \mathrm{~h}$ post-SCI ( $p<0.005)$, but not in any of the other post$\mathrm{SCI}$ groups. Due to these changes in muscarinic mRNA expression, the $\mathrm{M}_{2} / \mathrm{M}_{3}$ ratio had significantly increased in bladders at $24 \mathrm{~h}$ post-SCI $(p<0.05)$ and at $3 \mathrm{wk}$ post-SCI $(p<0.005)$.

\section{Discussion}

Most research on mechanisms underlying NDO has focussed on changes in the neural pathways [2,7]. It is, however, becoming more and more clear that changes in ACA might also contribute to the clinical image of NDO. 

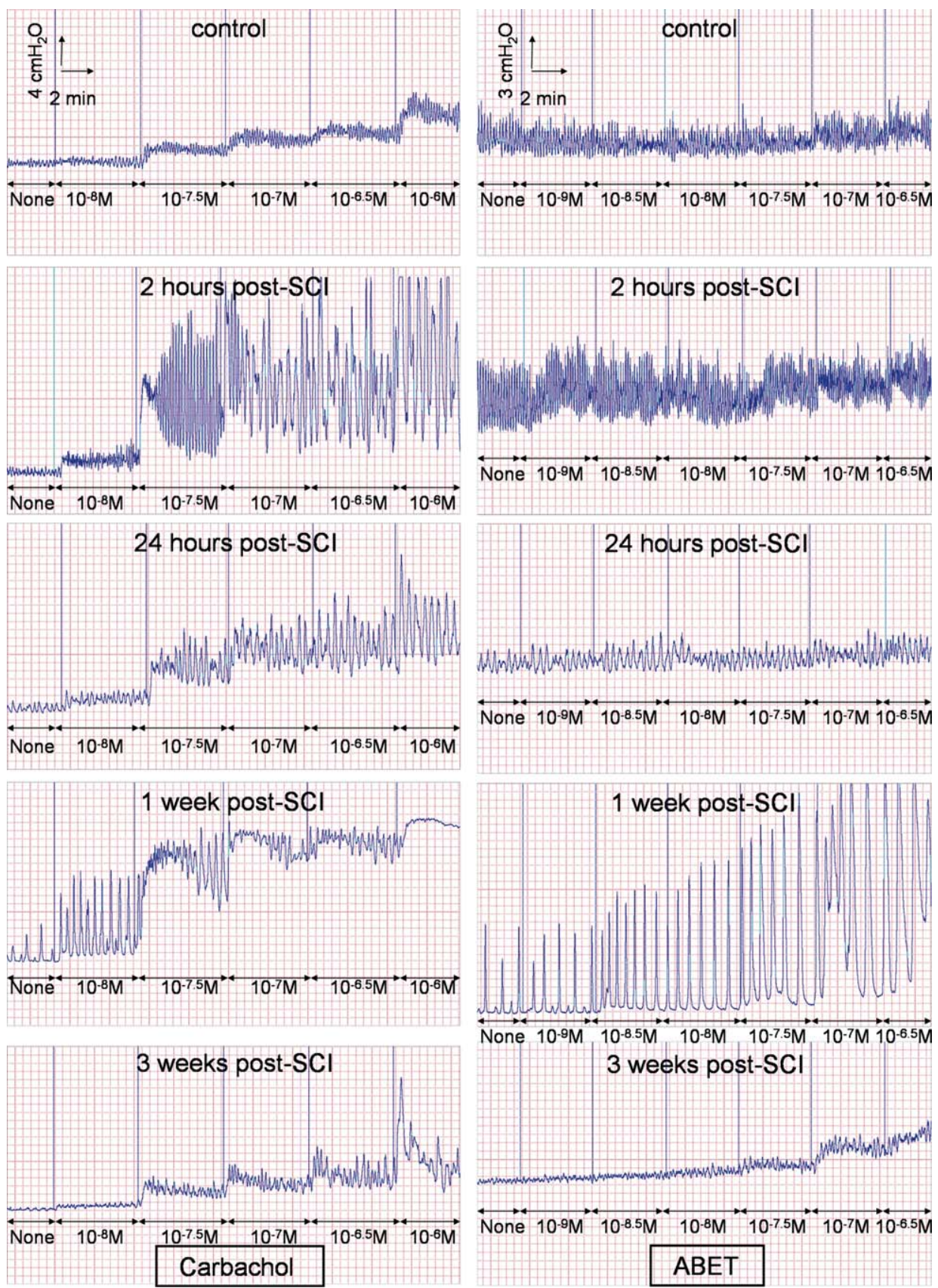

Fig. 4 - Original records show effects of cumulative doses of muscarinic agonists [carbachol and arecaïdine but-2-ynyl ester tosylate (ABET)] on autonomous contractile activity (ACA) in all post-spinal cord injury (post-SCI) groups. Pressure and time scales used in left and right panels are the same.

Early evidence for this thesis came from data on obstructed [5] and neurogenic bladders [3,6,12], and the present study further supports such theory. The decreased ACA (in frequency of transients and spikes) at $1 \mathrm{wk}$ post-SCI might play a role in the clinical manifestation of urine retention, while the unstable ACA (increased frequency of spikes) at 3 wk post-SCI could be partially responsible for the sensation of urgency and the emergence of NDO. The observed ACA at $7 \mathrm{~d}$ post-SCI might be due to a chronic absence of interaction with neural pathways, while neural sprouting post-SCI might induce and/or facilitate the increased and unstable ACA as seen at $3 \mathrm{wk}$ post-SCI. Bladder hypertrophy might also be an aetiological factor in the changing ACA post-SCI, otherwise alterations in ACA might facilitate the emergence of axonal sprouting and the recovery of voiding. As suggested by others, increased ACA could be an endogenous mechanism to increase afferent signalling in an attempt to re-establish voiding reflexes $[6,13]$.

It is known that bladder-wall compliance may decrease in bladders from chronic SCI patients $[14,15]$. In SCI rats it was demonstrated with in vitro [16] and in vivo [7] experiments that $3 \mathrm{wk}$ post-SCI there is a significant increase in bladder compliance. In the present series of experiments we confirmed this increase in bladder com- 

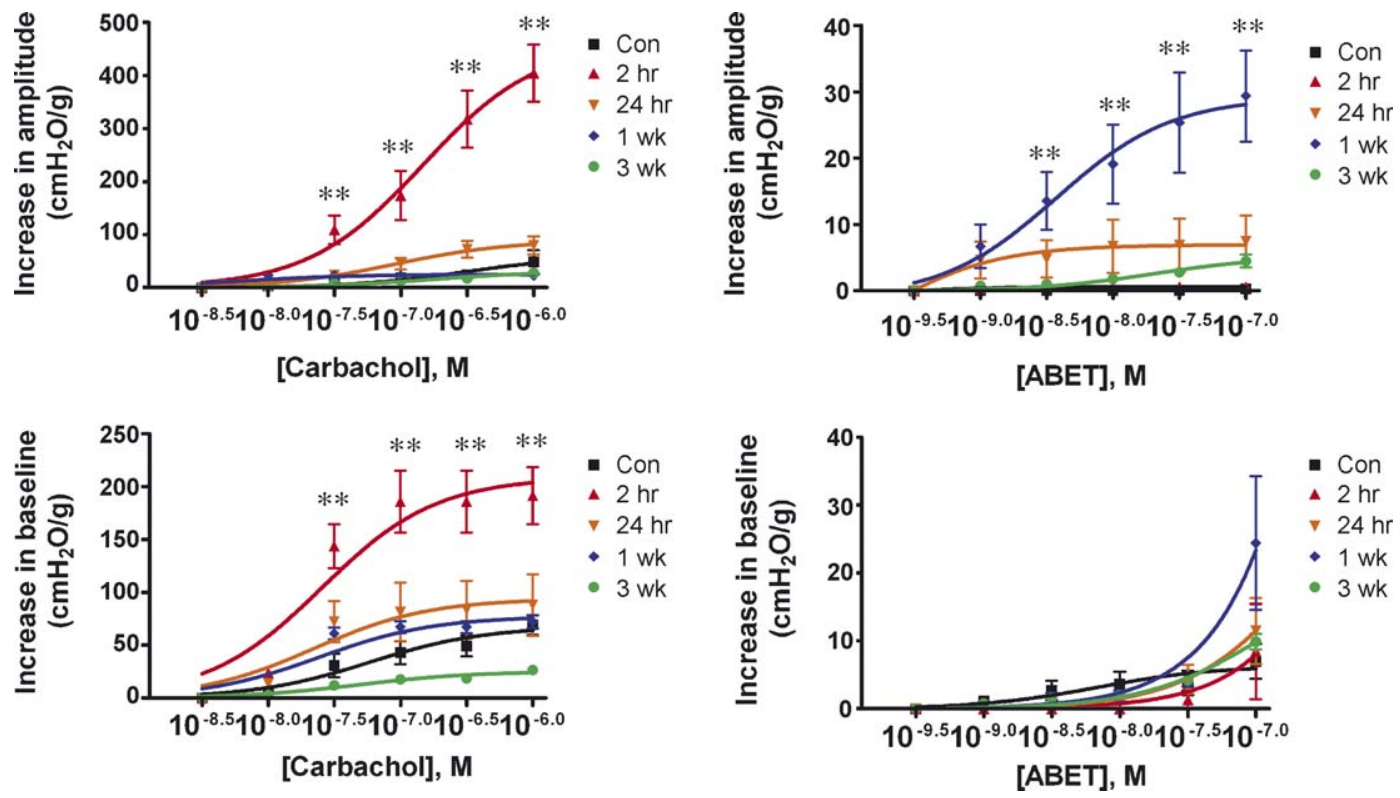

Fig. 5 - Graphs illustrate effects of muscarinic agonists [carbachol and arecaïdine but-2-ynyl ester tosylate (ABET)] on the amplitude of transients and contractile baselines in all groups post-spinal cord injury (post-SCI). An asterisk $\left({ }^{*}\right)$ indicates significance $\left({ }^{*} p<0.05 ;{ }^{* *} p<0.005\right)$. Significance values in bladders post-SCI were always compared to normal bladder values. Only the most relevant significances are indicated. Data are means plus or minus SE.
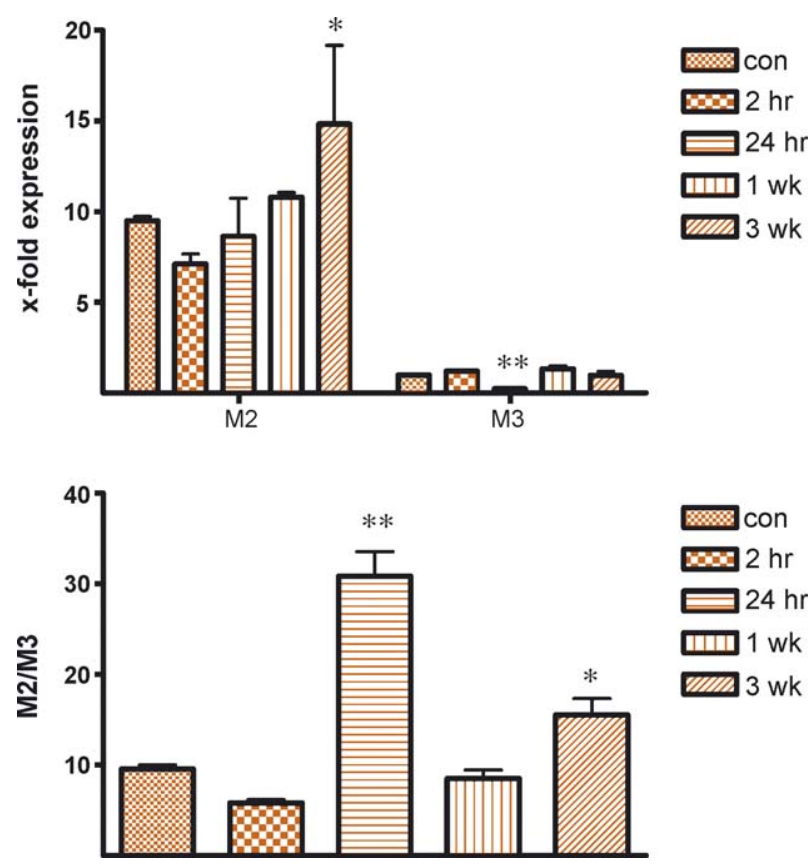

Fig. 6 - Quantitative polymerase chain reaction (QPCR) analysis of $\mathrm{M}_{2}$ and $\mathrm{M}_{3}$ mRNA expression post-spinal cord injury (post-SCI) in rat bladder. Upper graph: Relative quantification of $M_{2}$ and $M_{3}$ mRNA expression in full bladders at $2 \mathrm{~h}, 24 \mathrm{~h}, 1 \mathrm{wk}$, and 3 wk post-SCI compared to controls. One endogenous control, $\beta$-actin, was used for normalisation. Data are shown as $x$-fold expressions of detected mRNA normalised to $M_{3}$ mRNA in bladders of adult rats, which was used as a calibrator for the comparative critical threshold $(\Delta \Delta C t)$ analysis. Data are from four to six samples for each group. Data are means plus or minus SE. An asterisk ( $\left.{ }^{*}\right)$ indicates significance $\left({ }^{*} p<0.05 ;{ }^{* *} p<0.005\right)$. Lower graph: ratio between $M_{2}$ and $M_{3}$ mRNA levels presented in the upper graph. Data are means plus or minus SE. An asterisk $\left({ }^{*}\right)$ indicates significance $\left({ }^{*} p<0.05\right.$ and $\left.{ }^{* *} p<0.005\right)$. pliance through a different in vitro experimental approach. However, our observations might begin to explain the discrepancies between increased compliance in bladders from early SCI rats and the increased stiffness of bladders from chronic SCI patients. The different voiding behaviour in both groups could subject the structures of the bladder wall to different mechanical environments: sustained distension in areflexive (and beginning overactive) bladders $[7,16]$ as opposed to increased work and dynamic pressure load in long-term overactive bladders [14,15], which might then result in increased and decreased compliance respectively. The observation in this study that in bladders from rats with beginning NDO compliance ( $3 \mathrm{wk}$ post-SCI) had already decreased seems to affirm this idea.

Acetylcholine (Ach) is an important efferent neurotransmitter in bladder and $\mathrm{M}_{3}$ the muscarinic receptor subtype that directly mediates contractions (for review see Hegde [17]). Various changes in cholinergic bladder physiology have been reported post-SCI in rat $[2,8]$ and in the present study we found evidence for SCI-related increased sensitivity to muscarinic agonists.

It is remarkable that, with the two agonists used, the increased contractile response of ACA occurred at different times: carbachol had an increased response only at $2 \mathrm{~h}$ post$\mathrm{SCI}$, while the increased effects of ABET were noticed between $24 \mathrm{~h}$ and $3 \mathrm{wk}$ post-SCI, with a peak at $1 \mathrm{wk}$ postSCI. The increased carbachol effects at $2 \mathrm{~h}$ post-SCI are possibly due to acute denervation supersensitivity as described by others $[18,19]$. The mechanisms underlying the ABET effects remain mainly unclear with respect to the present data, although the weak $\mathrm{M}_{2}$-preference might be involved. There are many reports on changed $\mathrm{M}_{2}$-signalling in the neurogenic bladder. Despite its predominance in bladder [20], $\mathrm{M}_{2}$ normally only has indirect effects on 
$\mathrm{M}_{3}$-signalling [21]. In decentralised rat bladders an enhanced and direct contractile role for $\mathrm{M}_{2}$ has been reported [19]. Similar results were found in obstructed [22] and neurogenic $[3,23]$ rat bladders. The weak $\mathrm{M}_{2}$-preference of ABET might then be partially responsible for the increased contractile effects of ABET on ACA in bladders post-SCI, if these bladders indeed have an enhanced $\mathrm{M}_{2}$ function. To confirm this hypothesis, selective antagonist studies should be performed in future experiments. In humans such changed $\mathrm{M}_{2}$-function might also develop in NDO, although there are conflicting reports on this topic. Some authors reported that bladder tissue from patients suffering from NDO showed a shift from $M_{3}$ towards $M_{2}$ in direct mediation of bladder contractions [24], whereas others found that $\mathrm{M}_{3}$ was still responsible for muscarinicinduced contractions in neurogenic bladders with no changes in $\mathrm{M}_{2}$ signalling [25].

Further study of cholinergic changes post-SCI was performed at the mRNA level. We found a significant increase of $\mathrm{M}_{2}$ mRNA at $3 \mathrm{wk}$ post-SCI and a significant decrease of $\mathrm{M}_{3}$ mRNA at $24 \mathrm{~h}$ post-SCI. The observed increase in $M_{2}$ mRNA is likely to correlate with an elevated expression of $\mathrm{M}_{2}$ receptors since an increased density of $\mathrm{M}_{2}$ protein has been reported in decentralised [19], obstructed [22], and neurogenic [23] rat bladders. The behaviour of $\mathrm{M}_{3}$ mRNA in bladders post-SCI seems to correlate less with the expression of $\mathrm{M}_{3}$ protein since in hypertrophied [22] and (spontaneous voiding) neurogenic [23] rat bladders a decrease of $\mathrm{M}_{3}$ protein amount has been reported. Similar noncorrelating findings have been reported before [26] and suggest differences in the cascade from mRNA to protein between $M_{2}$ and $M_{3}$. The observed changes at the mRNA level are likely to be involved in the increased sensitivity for muscarinic agonists post-SCI, but the exact mechanisms remain unclear from the present study. Changes in muscarinic downstream signalling might also be involved, as suggested by others [27].

\section{Conclusion}

In conclusion we have presented further evidence for changed ACA in the neurogenic bladder. Besides being essential for the aetiology and symptoms of NDO, changed ACA in functional bladder disorders might also offer new therapeutic approaches. Interacting on local targets could be promising in new treatments for NDO, due to the possible advantage of fewer side-effects and less disturbance of normal voiding pathways. Based on the present data, it might then be interesting to further explore the mechanisms and receptor subtypes involved in the observed increased sensitivity to muscarinic agonists.

\footnotetext{
Author contributions: Thomas Gevaert had full access to all the data in the study and takes responsibility for the integrity of the data and the accuracy of the data analysis.
}

Study concept and design: Gevaert, De Ridder, van Leuven. Acquisition of data: Gevaert, van Leuven, Owsianik, Everaerts. Analysis and interpretation of data: Gevaert, Everaerts.
Drafting of the manuscript: Gevaert, Hutchings, De Ridder.

Critical revision of the manuscript for important intellectual content: De Ridder, Nilius, Hutchings.

Statistical analysis: Owsianik, Gevaert.

Obtaining funding: De Ridder, Nilius, Gevaert.

Administrative, technical, or material support: Owsianik.

Supervision: De Ridder, Nilius.

Other (specify): None.

Financial disclosures: I certify that all conflicts of interest, including specific financial interests and relationships and affiliations relevant to the subject matter or materials discussed in the manuscript (eg, employment/ affiliation, grants or funding, consultancies, honoraria, stock ownership or options, expert testimony, royalties, or patents filed, received, or pending), are the following: Wouter Everaerts is a doctoral fellow of the Fonds Voor Wetenschappelijk Onderzoek (Fund for Scientific Research; Flanders, Belgium).

Funding/Support and role of the sponsor: This work was supported by the Belgian Federal Government, the Flemish Government, the Onderzoeksraad KU Leuven (GOA 2004/07, FWO G.0136.00; FWO G.0172.03, Interuniversity Poles of Attraction Program, Prime Ministers Office IUAP Nr.3P6/23, Excellentiefinanciering $\mathrm{EF} / 95 / 010$ ), and grants from WOMS (research fund for multiple sclerosis, to DDR) and Charcot Foundation (to DDR) for collection of the data and management of the data.

\section{Appendix A. Supplementary data}

Supplementary data associated with this article can be found, in the online version, at doi:10.1016/j.eururo.2008. 06.064 .

\section{References}

[1] Abrams P, Cardozo L, Fall M, et al. The standardisation of terminology of lower urinary tract function: report from the Standardisation Sub-committee of the International Continence Society. Am J Obstet Gynecol 2002;187:116-26.

[2] De Groat WC. A neurologic basis for the overactive bladder. Urology 1997;50(Suppl 6A):36-52.

[3] Gevaert T, Ost D, de Ridder D. Comparison study of autonomous activity in bladders from normal and paraplegic rats. Neurourol Urodyn 2006;25:368-80.

[4] Drake MJ, Mills IW, Gillespie JI. Model of peripheral autonomous modules and a myovesical plexus in normal and overactive bladder function. Lancet 2001;358:401-3.

[5] Drake MJ, Hedlund P, Harvey I, Pandita R, Andersson K, Gillespie J. Partial outlet obstruction enhances modular autonomous activity in the isolated rat bladder. J Urol 2003;170:276-9.

[6] Drake MJ, Re: Gevaert T, Ost D, de Ridder D. Comparison study of autonomous activity in bladders from normal and paraplegic rats. Neurourol Urodynam 2006;25:379-80.

[7] Zinck ND, Rafuse VF, Downie JW. Sprouting of CGRP primary afferents in lumbosacral spinal cord precedes emergence of bladder activity after spinal injury. Exp Neurol 2007;204:777-90.

[8] Takahara Y, Maeda M, Nakatani T, Kiyama H. Transient suppression of the vesicular acetylcholine transporter in urinary bladder pathways following spinal cord injury. Brain Res 2007;1137:20-8.

[9] Yoshiyama M, Nezu FM, Yokoyama O, de Groat WC, Chancellor MB. Changes in micturition after spinal cord injury in conscious rats. Urology 1999;54:929-33.

[10] Tumiatti V, Wehrle J, Hildebrandt C, et al. Muscarinic properties of compounds related to arecaidine propargyl ester. Arzneimittelforschung 2000;50:11-5. 
[11] Gevaert T, Vandepitte J, Ost D, Nilius B, de Ridder D. Autonomous contractile activity in the isolated rat bladder is modulated by a TRPV1 dependent mechanism. Neurourol Urodyn 2007;26:424-32, discussion 451-3.

[12] Ikeda Y, Fry C, Hayashi F, Stolz D, Griffiths D, Kanai A. Role of gap junctions in spontaneous activity of the rat bladder. Am J Physiol Renal Physiol 2007;293:F1018-25.

[13] Gillespie JI. The autonomous bladder: a view of the origin of bladder overactivity and sensory urge. BJU Int 2004;93:478-83.

[14] Hackler RH, Hall MK, Zampieri TA. Bladder hypocompliance in the spinal cord injury population. J Urol 1989;141:1390-3.

[15] Weld JD, Graney MJ, Dmochowski RR. Differences in bladder compliance with time and associations of bladder management with compliance in spinal cord injured patients. J Urol 2000;163: 1228-33.

[16] Gloeckner DC, Sacks MS, Fraser MO, Somogyi GT, de Groat WC, Chancellor MB. Passive biaxial mechanical properties of the rat bladder wall after spinal cord injury. J Urol 2002;167:2247-52.

[17] Hegde SS. Muscarinic receptors in the bladder: from basic research to therapeutics. Br J Pharmacol 2006;147(Suppl 2):S80-7.

[18] Mattiasson A, Andersson KE, Sjögren C, Sundin T, Uvelius B. Supersensitivity to carbachol in the parasympathetically decentralized feline urinary bladder. J Urol 1984;131:562-5.

[19] Braverman AS, Luthin GR, Ruggieri MR. $\mathrm{M}_{2}$ muscarinic receptor contributes to contraction of the denervated rat urinary bladder. Am J Physiol 1998;275:R1654-60.
[20] Wang P, Luthin GR, Ruggieri MR. Muscarinic acetylcholine receptor subtypes mediating urinary bladder contractility and coupling to GTP binding proteins. J Pharmacol Exp Ther 1995;273:959-66.

[21] Ehlert FJ, Griffin MT, Abe DM, et al. The $\mathrm{M}_{2}$ muscarinic receptor mediates contraction through indirect mechanisms in mouse urinary bladder. J Pharmacol Exp Ther 2005;313:368-78.

[22] Braverman AS, Ruggieri Sr MR. Hypertrophy changes the muscarinic receptor subtype mediating bladder contraction from M3 toward M2. Am J Physiol Regul Integr Comp Physiol 2003;285:R701-8.

[23] Braverman A, Legos J, Young W, Luthin G, Ruggieri M. $\mathrm{M}_{2}$ receptors in genito-urinary smooth muscle pathology. Life Sci 1999;64: 429-36.

[24] Pontari MA, Braverman AS, Ruggieri Sr MR. The M2 muscarinic receptor mediates in vitro bladder contractions from patients with neurogenic bladder dysfunction. Am J Physiol Regul Integr Comp Physiol 2004;286:R874-80.

[25] Stevens LA, Chapple CR, Chess-Williams R. Human idiopathic and neurogenic overactive bladders and the role of $\mathrm{M}_{2}$ muscarinic receptors in contraction. Eur Urol 2007;52:531-8.

[26] Braverman AS, Ruggieri Sr MR. Muscarinic receptor transcript and protein density in hypertrophied and atrophied rat urinary bladder. Neurourol Urodyn 2006;25:55-61.

[27] Braverman AS, Tallarida RJ, Ruggieri Sr MR. Interaction between muscarinic receptor subtype signal transduction pathways mediating bladder contraction. Am J Physiol Regul Integr Comp Physiol 2002;283:R663-8.
Editorial Comment on: The Loss and Progressive

Recovery of Voiding after Spinal Cord Interruption in

Rats is Associated with Simultaneous Changes in

Autonomous Contractile Bladder Activity

Masayuki Takeda

Department of Urology, Interdisciplinary Graduate

School of Medicine and Engineering,

University of Yamanashi, Shimokato Chuo City,

Yamanashi 409-3898, Japan

matakeda@yamanashi.ac.jp

This study is unique and interesting because a very rapid, in vivo experiment just after sacrifice with excised whole urinary bladder had been done. The authors strongly pointed out that the autonomous contractile activity (ACA) is very important for the pathophysiology of neurogenic detrusor overactivity (NDO) in spinal cord injured (SCI) rats. Exaggerated and increased ACA might be partially responsible for generating nonvoiding contractions (NVC) and increased sensation of urge [1-3]. In both acute $\mathrm{SCI}$ with areflexic stage and renewed voiding phase (3 wk after $\mathrm{SCI}$ ), M2 receptor might be rather strongly related to ACA. Hence, the possibility of M2 receptor selective antagonist or agonist in some stage of SCI might be useful, as previously published [4]. For the guarantee of pharmacological evaluation, mRNA expression or protein expression studies are important and should be done.

In these experiments, changes in local bladder function could be seen using excised bladder without the effect of central innervations. In addition, the implication of muscarinic receptor subtypes in the change of ACA might be evaluated. However, recent papers suggested that changes in both afferent innervations and urothelial function might be very important [5]. In these experimental methods, afferent nerve function, local reflex arc, and urothelial function cannot be evaluated. In addition to these shortcomings, muscarinic receptor subtypes could not be fully evaluated.

\section{References}

[1] Gevaert T, Owsianik G, Hutchings G, et al. The loss and progressive recovery of voiding after spinal cord interruption in rats is associated with simultaneous changes in autonomous contractile bladder activity. Eur Urol 2009;56:168-76.

[2] Gevaert T, Ost D, de Ridder D. Comparison study of autonomous activity in bladders from normal and paraplegic rats. Neurourol Urodyn 2006;25:368-80.

[3] Drake MJ, Re: Gevaert T, Ost D, de Ridder D. Comparison study of autonomous activity in bladders from normal and paraplegic rats. Neurourol Urodynam 2006;25:379-80.

[4] Pontari MA, Braverman AS, Ruggieri Sr MR. The M2 muscarinic receptor mediates in vitro bladder contractions from patients with neurogenic bladder dysfunction. Am J Physiol Regul Integr Comp Physiol 2004;286:R874-80.

[5] Salas NA, Somogyi GT, Gangitano DA, et al. Receptor activated bladder and spinal ATP release in neurally intact and chronic spinal cord injured rats. Neurochem Int 2007;50:345-50.

DOI: 10.1016/j.eururo.2008.06.065

DOI of original article: 10.1016/j.eururo.2008.06.064 